\title{
Comunidades bacterianas involucradas en el ciclo del nitrógeno en humedales construidos
}

ENVIRONMENTAL ENGINEERING

\section{Bacterial communities involved in the nitrogen cycle in constructed wetlands}

\author{
Norma R. Pérez-Peláez", Miguel R. Peña-Varón ${ }^{* *}$, Janeth Sanabria ${ }^{\S^{*}}$ \\ *Escuela de Ingeniería de Recursos Naturales y del Ambiente, EIDENAR. Universidad del Valle. \\ Grupo de Procesos Avanzados para Tratamientos Químicos y Biológicos, Cali, Colombia. \\ normaperez@udec.cl, ${ }^{s}$ janeth.sanabria@correounivalle.edu.co \\ **Instituto Cinara, Grupo GISAM, Universidad del Valle, Cali, Colombia. \\ miguel.pena@correounivalle.edu.co
}

(Recibido: Julio 26 de 2010 - Aceptado: Noviembre 3 de 2011)

\begin{abstract}
Resumen
La elevada producción de agua residual y su falta de tratamiento ha llevado a la búsqueda de sistemas de depuración eficiente, económica, fácil de operar y que permitan considerar el agua residual como un recurso. Los humedales construidos son sistemas de tratamiento promisorios para este fin, pero la investigación de los microorganismos involucrados en la transformación de los nutrientes en éstos es aún incipiente. En este estudio se reportan los resultados de la evaluación de poblaciones de bacterias nitrificantes, heterotróficas y fijadoras de nitrógeno presentes en el medio de soporte, en este caso grava y columna de agua en tres humedales construidos (HC) sometidos a distintas cargas hidráulicas y con diferentes especies vegetales: Phragmites australis, Heliconia psittacorum y uno sin vegetación como control. El humedal con P. australis presentó mayores densidades de bacterias nitrificantes y fijadoras de Nitrógeno (5.35 y 7.18 unidades $\log$ gr- ${ }^{1}$, respectivamente); el humedal con H. psittacorum presentó las menores densidades para todos los grupos de bacterias y el humedal control mostró la mayor densidad de bacterias heterótrofas (7.22 unidades $\log$ gr- $^{1}$ ). El número de bacterias de las poblaciones encontradas, sugiere la importante actividad metabólica y dinámica de estos microorganismos en los sistemas de humedales construidos en el trópico.
\end{abstract}

Palabras Clave: Humedales Construidos, Nitrificación, Fijación de Nitrógeno, Phragmites australis, Heliconia psittacorum.

\begin{abstract}
The high wastewater production rate and its lack of treatment is forcing the search for treatment systems that are efficient, economic, easy to operate and maintain. Additionally, the effluent reuse or reclamation must be considered in any modern wastewater treatment system. Constructed wetlands represent a promising technology in this respect, however, the knowledge and research on the microbial processes involved in the biodegradation of contaminants is still under development. This work reports on the evaluation of heterotrophic, nitrifying and nitrogen fixing bacterial groups present in the support media (gravel) and water column of three constructed wetlands (Cws). These latter are working under different hydraulic loading rates and with different plant species: Phragmites australis, Heliconia psittacorum or without vegetation. The highest densities of nitrifying and $\mathrm{N}_{2}$-fixing bacteria (5.35 and $7.18 \log$ units gr- ${ }^{1}$, respectively) were found with P. australis, while the CW loaded with H. psittacorum exhibited the lowest densities regardless of the tested bacterial groups. Finally, the unplanted CW showed the highest density of heterotrophic bacteria (7.22 log units gr- ${ }^{-1}$ ). In conclusion, the high bacterial counts found in this study suggest that an important metabolic activity and an interesting bacterial dynamics take place within CWs units operated in the tropics.
\end{abstract}

Keywords: Constructed wetlands, Nitrification, Nitrogen fixation, Phragmites australis, Heliconia psittacorum. 


\section{Introducción}

El crecimiento demográfico y las actividades humanas relacionadas con la industrialización, la producción de bienes de consumo y la agricultura, demandan grandes cantidades de agua. En Colombia, se estima que la producción diaria de residuos líquidos supera los cuatro millones de metros cúbicos y aunque existen políticas que impiden que las aguas residuales se depositen directamente en ríos y mares sin tratamiento previo, (Ministerio del Medio Ambiente, 2002), los recursos y la eficiencia de los tratamientos son escasos. Sólo el $8 \%$ de las aguas residuales se tratan de alguna manera antes de descargarse en las fuentes naturales. En países en vía de desarrollo, los sistemas de tratamiento de agua residual empleados deberían ser eficientes, de bajo costo y por lo tanto sostenibles para la comunidad beneficiaria, EPA(2002).

Los humedales construidos cumplen con estos requisitos y permiten utilizar el agua de una manera más eficiente (i.e., mediante la recirculación, el re-uso y el reciclaje), Wetzel (2001).

Las investigaciones existentes en la región, describen los mecanismos de tratamientos de aguas residuales como porcentajes de eliminación. En sistemas ubicados en países con estaciones se ha hecho mas énfasis en el estudio microbiológico, Faulwetter et al (2009); Truu et al (2009). Sin embargo, estos estudios difieren en temperatura, luminosidad y pluviosidad con el trópico y se desconoce si ocurre lo mismo con el componente microbiológico y su relación con la eficiencia de los tratamientos. Los nutrientes de mayor importancia en el agua residual doméstica son el nitrógeno y el fósforo, elementos esenciales para el crecimiento de plantas y microorganismos, Stottmeister et al (2003); Bitton (2005).

No obstante, existen varios mecanismos posibles para la eliminación de nitrógeno en los humedales construidos: la asimilación por parte de las plantas, la nitrificación y desnitrificación microbiana, la absorción en el sustrato y la volatilización. Se ha estimado que sólo el 10\% de la carga aplicada de nitrógeno es asimilada por las plantas. Así mismo, el $\mathrm{pH}$ y las temperaturas se encuentran fuera del rango óptimo para la volatilización del amonio (Paredes et al, 2007). Por lo tanto, en los procesos de transformación del nitrógeno están involucrados principalmente los microorganismos, con procesos metabólicos como la nitrificación y la desnitrificación. En la nitrificación el amonio se convierte a nitrato por dos grupos de bacterias filogenéticamente distintas como las oxidantes de amonio y las oxidantes de nitrito, (Bock \& Koop, 2006) y en la desnitrificación, el nitrato se convierte a nitrógeno gaseoso, (Bitton, 2005; Brittain et al, 1992), completando así la eliminación del nitrógeno de los sistemas.

Adicionalmente en la fijación de nitrógeno, el $\mathrm{N}_{2}$ atmosférico se convierte en amonio, (Moat et al, 2002; Dixon \& Kahn, 2004). Este metabolismo se ha descubierto y explicado en muchos ecosistemas asociado a procariotas (Eubacterias y Archaeas), que poseen el complejo enzimático nitrogenasa (Madigan, 2004). Se sabe poco sobre la participación de estos microorganismos en términos de su eficiencia de transformación sobre compuestos de nitrógeno en humedales construidos. Phragmites australis, la planta que se usó en esta investigación es una planta de distribución cosmopolita, presente en todos los continentes. Los estudios en esta especie reportan altos niveles de remoción de sólidos suspendidos, demanda química de oxigeno (DQO) y parásitos (Quipuzco, 2002). En algunos estudios se ha reportado la remoción del $54 \%$ de los compuestos nitrogenados presentes en el agua residual de humedales (Senzia et al, 2003). No existen referencias sobre el uso de $H$. psittacorum en la remoción de contaminantes de agua residual ni de las comunidades rizosféricas de esta planta nativa de nuestros bosques húmedos tropicales. Es importante explorar la eficiencia de macrófitas autóctonas del trópico mediante estudios que permitan conocer el desempeño de las plantas y sus comunidades rizosféricas en la remoción de contaminantes de los sistemas de tratamiento de agua residual.

El objetivo de este estudio fue evaluar los cambios de densidades de algunas poblaciones de bacterias que degradan materia orgánica y compuestos nitrogenados como lo son las bacterias heterótrofas, fijadoras de nitrógeno y nitrificantes 
respectivamente, en humedales construidos de flujo sub-superficial para tratamiento de aguas residuales domésticas, ubicados en la región sur occidental de Colombia.

\section{Metodología}

\subsection{Sitio de muestreo}

El estudio se realizó en tres humedales construidos de flujo sub-superficial ubicados en la estación de investigación en tratamiento de agua residual domestica de Ginebra, Valle del Cauca. Estos humedales funcionan con flujo continuo y realizan un tratamiento secundario, ya que reciben el efluente de una laguna anaeróbica a escala real. Los sistemas se plantaron con Phragmites australis, Heliconia psittacorum y el control sin vegetación.

Las cargas hidráulicas a la que se sometieron todos los sistemas fueron 1.7, 2.6 y $3.5 \mathrm{~m}^{3} \mathrm{~d}^{-1}$ con una duración de 6 meses para cada carga. La toma de muestras se realizó desde marzo del 2006 hasta septiembre del 2007 con una frecuencia mensual y total de siete muestreos. Se muestrearon las zonas del substrato cercanas a la rizosfera o del sustrato solamente para el caso del sistema sin plantas. Para conocer la distribución longitudinal de los microorganismos dentro de los humedales se ubicaron pozos de muestreo en $\mathrm{L} / 3$ y $2 \mathrm{~L} / 3$. Para poder muestrear la fase acuosa, se introdujo un tuvo de PVC en cada una de estas zonas. El muestreo se hizo de forma aleatoria en el tiempo, durante varias semanas asumiendo cada muestreo como repeticiones (Figura 1).

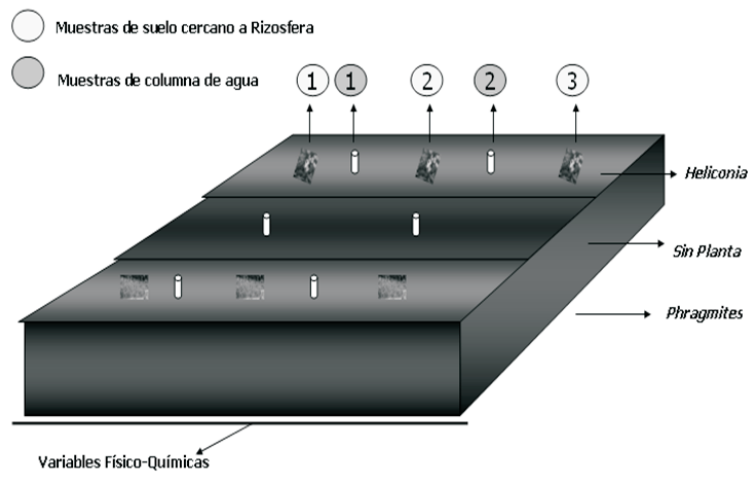

Figura 1. Diagrama de las zonas muestreadas en los humedales.
Además de los análisis y mediciones microbianas, se realizaron mediciones de $\mathrm{pH}$, temperatura, demanda biológica de oxigeno (DBO), potencial de óxido-reducción (ORP), concentraciones de amonio y nitrito presentes en el agua residual según los protocolos de los métodos estandarizados APHA(2005).

\subsection{Cuantificación de Bacterias}

Para el recuento de todos los grupos bacterianos se realizaron diluciones seriadas (a partir de $1 \mathrm{gr}$ de las muestras de sustrato o $1 \mathrm{~mL}$ de las muestras de columna de agua) en solución salina estéril al .8\% $(\mathrm{pH}=7.0)$. Para separar las bacterias; muestras de un gramo se suspendieron en solución salina hasta completar un volumen de $100 \mathrm{~mL}$. La solución se agitó durante $15 \mathrm{~min}$ y alícuotas de $1 \mathrm{~mL}$ se tomaron para hacer diluciones sucesivas. Cada tubo de dilución se agitó durante unos 15 segundos aproximadamente antes de inocularse a las cajas de petri con el medio de cultivo. Las bacterias heterótrofas se aislaron en placas mediante siembra en profundidad usando Agar nutritivo, y se incubaron a $35^{\circ} \mathrm{C}$ (BINDER BD400; Binder $\mathrm{GMBH}$, Alemania) durante 24 horas.

Las bacterias fijadoras de nitrógeno se contaron en placas usando el medio de cultivo libre de nitrógeno Ashby, Fowler (1934). Se cuantificaron las bacterias nitrificantes oxidadoras de nitrito usando el medio de cultivo con $0.1 \% \mathrm{v} / \mathrm{v}$ de solución elementos traza $\left(\mathrm{MnSO}_{4}, \mathrm{H}_{3} \mathrm{BO}_{3}, \mathrm{ZnSO}_{4}\right.$, $\left.\mathrm{FeSO}_{4}, \mathrm{CuSO}_{4}, \quad\left(\mathrm{NH}_{4}\right)_{6} \mathrm{Mo}_{7} \mathrm{O}_{24}\right), \quad 10 \%$ v/v de solución stock $\left(\mathrm{CaCO}_{3}, \mathrm{NaCl}, \mathrm{MgSO}_{4}, \mathrm{KH}_{2} \mathrm{PO}_{4}\right), 2$ $\mathrm{g} / \mathrm{L}$ deNaNO${ }_{2}$ y $15 \mathrm{~g} / \mathrm{L}$ de agar bacteriológico. Como control positivo se usó la cepa Nitrobacter winogradsky DSM 10237. El tiempo de incubación para los dos grupos fue de 14 días a $27^{\circ} \mathrm{C}$ (Precision Scientific, CO) Gaitan (2006); Pérez-Peláez (2006).

\subsection{Análisis estadístico}

Los datos de los parámetros fisicoquímicos se consideraron como covariables del estudio. Para evaluar la influencia de las variables en la cantidad de bacterias se realizaron análisis de covarianza $(\alpha=0,05)$, (Montgomery, 2002), usando las herramientas estadísticas de Minitab ${ }^{\circledR}$ 14. Se 
realizaron además pruebas de medias para cada grupo bacteriano usando el programa estadístico SYSTAT ${ }^{\circledR} 11$.

\section{Resultados y Discusión}

Para cada humedal los recuentos obtenidos entre los distintos puntos de muestreo del sustrato fueron similares, así como los promedios. Los resultados de las cuantificaciones de bacterias de las muestras de columna de agua también presentaron valores muy cercanos entre ellos.

\subsection{Comparaciones entre poblaciones presentes en el sustrato y en la columna de agua}

Esta comparación se realizó con el objetivo de evaluar la influencia de la cercanía de las plantas así como las condiciones ambientales favorables para la generación de biofilms en la densidad de los grupos medidos. La concentración de cada grupo de bacterias cuantificadas durante las tres cargas hidráulicas fue mayor en las muestras tomadas cerca a rizosfera que las de la columna de agua (Figura 2).

El recuento mínimo de bacterias en columna de agua fue de $4.08 \log 10$ UFC $\mathrm{mL}^{-1}$ y la cuantificación máxima de $9.03 \log 10$ UFC gr- $^{-}$. Es importante destacar que la población de bacterias fijadoras de Nitrógeno (mayor a 6 Log $10{\mathrm{UFC} \mathrm{gr}^{-}}^{-}$) se reporta por primera vez en estos sistemas.

\subsection{Influencia de la carga hidráulica en el recuento microbiano}

Las Figuras 3 y 4 muestran las variaciones que presentaron los grupos bacterianos en cada humedal, en cada caso se discriminó el tipo de muestra y la carga hidráulica.

Para las bacterias heterótrofas las mayores poblaciones se presentaron así: control 7.49 Log10 UFC gr- ${ }^{1}$ en c.h.II; P. australis 7.29 Log10 UFC gr- ${ }^{1}$ en c.h.II, H. psittacorum $7.19 \log 10$ de UFC gr- ${ }^{1}$ en c.h. I. Para las bacterias fijadoras de nitrógeno las mayores densidades se presentaron en el siguiente orden: P. australis 7.57 Log10 UFC gr- $^{1}$ en c.h. III, control $7.37 \log 10$ UFC gr- $^{1}$ en c.h II; H. psittacorum 6.79 Log10 UFC gr- ${ }^{1}$ en c.h. II. Para las bacterias nitrificantes: P. australis 5.94 $\log 10$ UFC gr- ${ }^{1}$ en c.h. I, control $5.16 \log 10$ UFC gr- $^{1}$ en c.h. III, H. psittacorum $5.11 \log 10 \mathrm{UFC} \mathrm{gr-}^{1}$ en c.h. II.

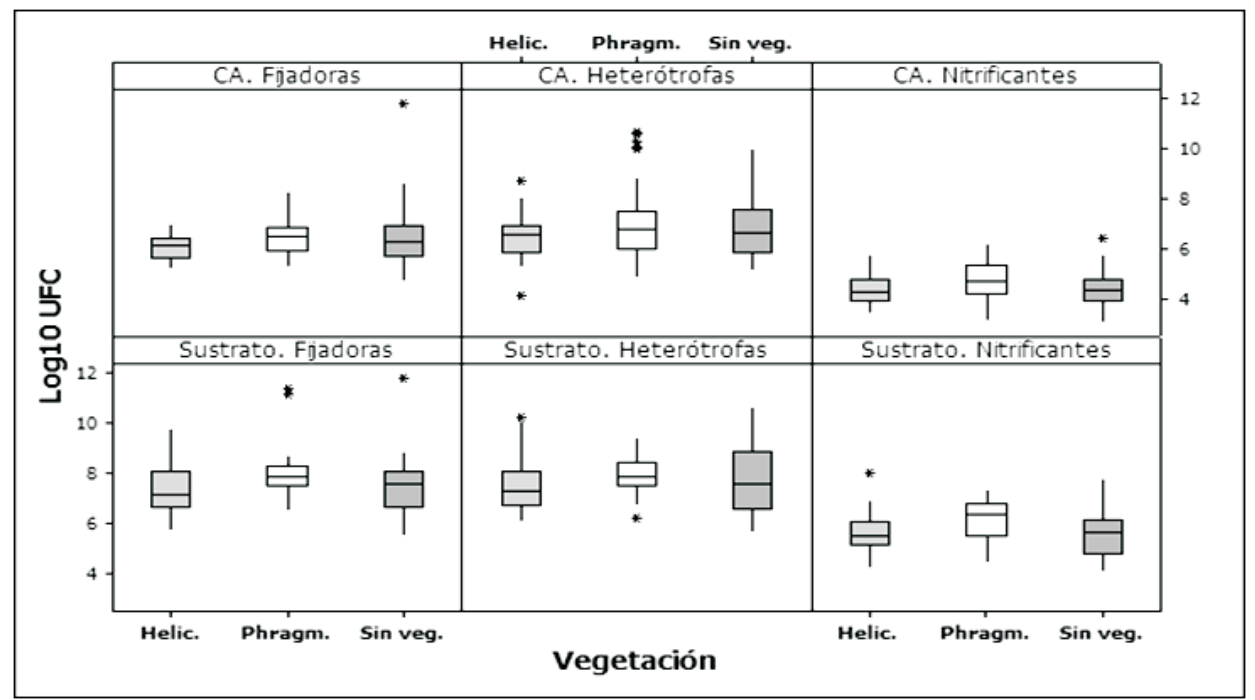

Figura 2. Distribución de Grupos Bacterianos en los humedales. CA: Columna de Agua; Helic: Humedal plantado con Heliconia psittacorum; Phragm: Humedal plantado con Phragmites australis; Sin veg: Humedal control. 


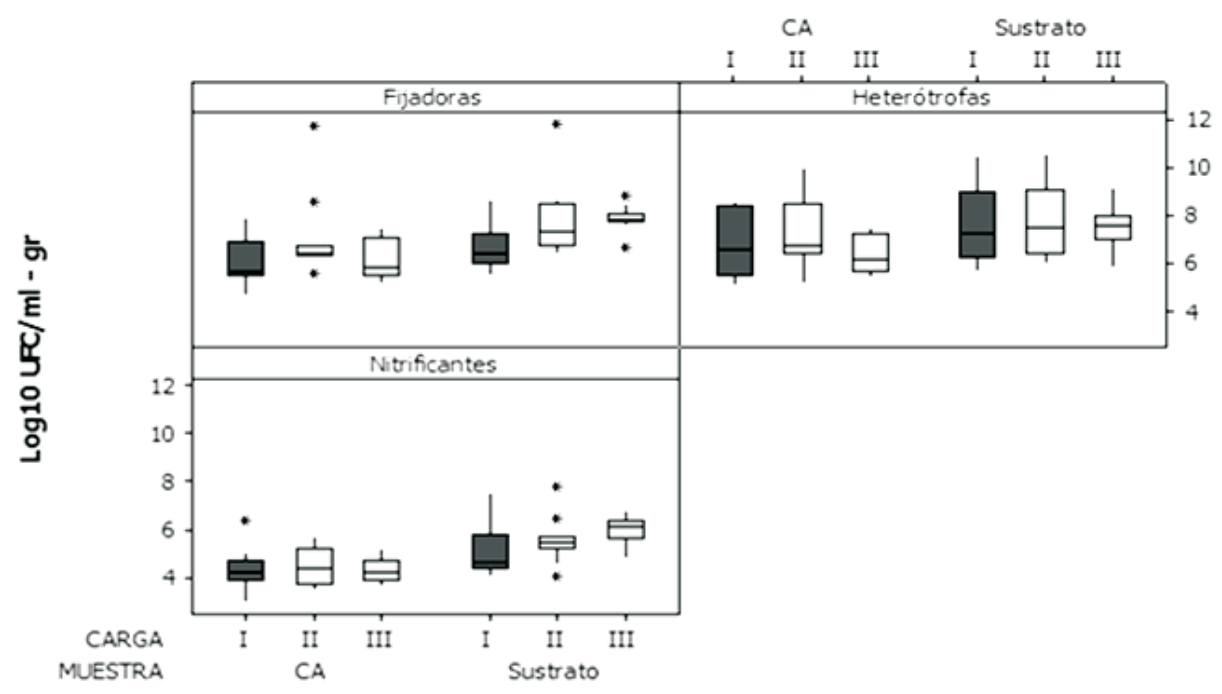

Figura 3. Distribución de Bacterias en el Humedal control. CA: Columna de Agua. En el eje x se muestran los niveles de la carga hidráulica (ch): I (Qd: $\left.1.7 \mathrm{~m}^{3} \mathrm{~d}^{-}{ }^{1}\right)$; II (Qd: $\left.2.6 \mathrm{~m}^{3} \mathrm{~d}^{-}\right)$y III (Qd: $\left.3.5 \mathrm{~m}^{3} \mathrm{~d}^{-}{ }^{1}\right)$.

a

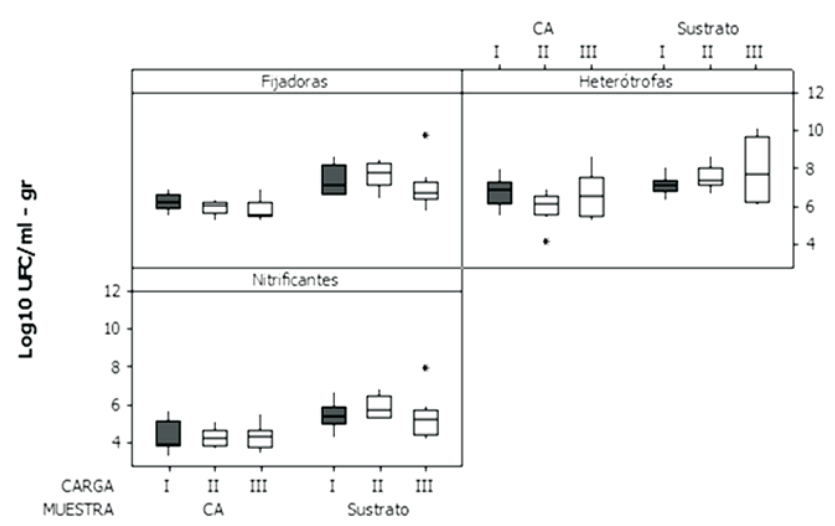

b

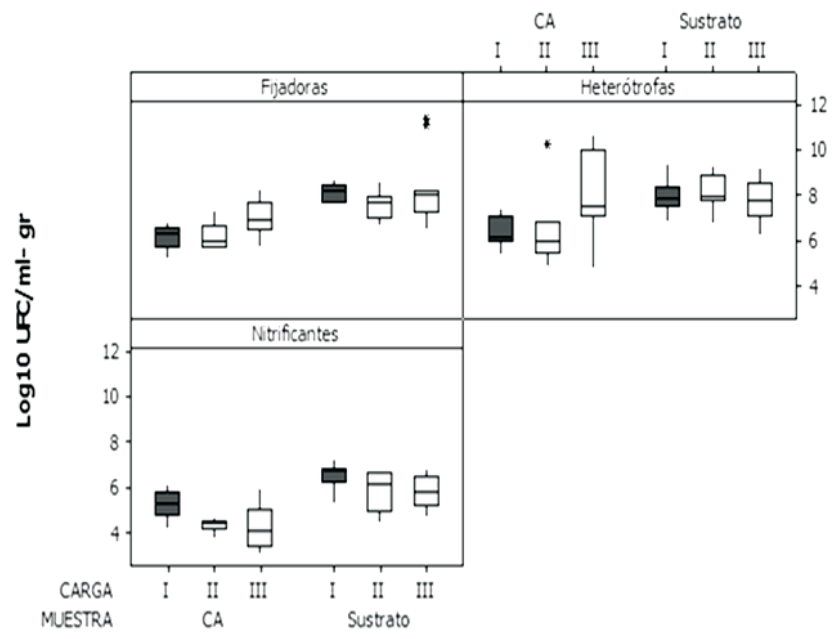

Figura 4. Distribución de Bacterias en el Humedal plantado con a) Heliconia psittacorum. b) Phragmites australis CA: Columna de Agua. En el eje x se muestran los niveles de la carga hidráulica (ch): I(Qd: $\left.\left.1.7 \mathrm{~m}^{3} \mathrm{~d}^{-}\right)^{\prime}\right)$;I (Qd: $2.6 \mathrm{~m}^{3}$ $\left.d^{l}\right)$ y III $\left(Q d: 3.5 m^{3} d^{l}\right)$. 
Para las bacterias heterótrofas las mayores poblaciones se presentaron así: control 7.49 Log10 UFC gr- ${ }^{1}$ en c.h.II; P. australis $7.29 \log 10$ UFC gr- ${ }^{1}$ en c.h.II, H. psittacorum $7.19 \log 10$ de UFC gr- ${ }^{1}$ en c.h. I. Para las bacterias fijadoras de nitrógeno las mayores densidades se presentaron en el siguiente orden: P. australis 7.57 Log 10 UFC gr- $^{1}$ en c.h. III, control $7.37 \log 10$ UFC ${ }^{1}{ }^{1}$ en c.h II; H. psittacorum 6.79 Log10 UFC gr- ${ }^{1}$ en c.h. II. Para las bacterias nitrificantes: P. australis 5.94 $\log 10$ UFC gr- $^{1}$ en c.h. I, control $5.16 \log 10$ UFC gr- $^{1}$ en c.h. III, H. psittacorum $5.11 \log 10$ UFC gren c.h. II.

\subsection{Influencia de la vegetación y el tipo de muestra.}

Las pruebas de media realizadas mostraron medias significativamente diferentes en todos los grupos para el tipo de muestra y en la interacción entre la vegetación y la carga hidráulica. Los resultados se muestran en la Tabla 1.

Los análisis de medias mostraron la relación entre el tipo de muestra y la abundancia de todos los grupos bacterianos. Se obtuvo cuantificaciones superiores en las muestras del sustrato que en las de la columna de agua de todos los tratamientos. Las bacterias heterótrofas presentaron medias significativamente diferentes con la interacción de todos los factores (vegetación, muestra y carga).

\subsection{Influencia de los parámetros fisicoquímicos}

Las pruebas de correlación realizadas no mostraron influencia de los parámetros fisicoquímicos en el crecimiento de los grupos bacterianos. La tabla 2 muestra los valores que presentó cada variable (mínimo y máximo) durante el periodo de muestreo.

Las técnicas de recuento usadas en esta investigación cuantificaron las bacterias viables en medios artificiales ajustados usando microorganismos de referencia. Los resultados muestran la presencia de los grupos medidos, en estos sistemas de tratamiento. Sin embargo, en medios artificiales de cultivo podría subestimarse la diversidad y abundancia de los diferentes grupos bacterianos pertenecientes a estos nichos,

Tabla 1. Análisis de Medias para todos los grupos bacterianos.

\begin{tabular}{lccccc}
\hline Factor & $\begin{array}{c}\text { Suma de } \\
\text { Cuadrados }\end{array}$ & Df & $\begin{array}{c}\text { Cuadrados } \\
\text { Medios }\end{array}$ & F-ratio & P \\
\hline $\begin{array}{l}\text { Nitrificantes* } \\
\text { Tipo de Muestra }\end{array}$ & 81.847 & 1 & 81.847 & 139.094 & 0.000 \\
Fijadoras* & 85.646 & 1 & 85.646 & 94.168 & 0.000 \\
Tipo de Muestra & & & & & \\
Heterotrofas* & 47.416 & 1 & 47.416 & 32.207 & 0.000 \\
Tipo de Muestra & & & & & \\
Heterotrofas* & 15.038 & 4 & 3.759 & 2.554 & 0.041 \\
Vegetacion* & & & & & \\
Carga & 14.322 & 4 & 3.581 & 2.432 & 0.049 \\
Heterótrofas* & & & & \\
Vegetación* & & & & & \\
Carga *Muestra & & & & & \\
\hline
\end{tabular}

* Variable que se fija para el analisis 
pero no cultivables. El ejemplo más sobresaliente hace referencia a los grupos anammox identificados con métodos moleculares en diversos ambientes incluidos los sistemas de tratamiento de aguas residuales (Xiao et al, 2009; Zehr, 2009; Sánchez \& Sanabria, 2009). Una evidencia clara de la presencia de estos microorganismos es la presencia de Bacterias fijadoras de Nitrógeno, si consideramos que los anammox son capaces de asimilar el amonio y convertirlo en $\mathrm{N}_{2}$., (Sanabria et al, 2009; Manser 2006). No obstante, las limitaciones de los métodos de cultivo, es de conocimiento que la reproducción bacteriana depende de su capacidad y disponibilidad de sustratos en el medio de tal forma que es válido asumir una relación entre actividad microbiana y presencia de microorganismos cultivables.
Por otra parte, si consideramos los sistemas de tratamiento como ambientes eutróficos, los resultados constituyen una importante aproximación a la dinámica de grupos microbianos de importancia creciente en el mundo, que permiten conocer la influencia de los procesos como la fijación de nitrógeno, la oxidación de nitrito y la heterotrofia, en los humedales construidos. Mucho del conocimiento en este campo se asumen por inferencia de procesos que ocurren en humedales naturales. Por lo que no hay mucha evidencia sobre algunos los consorcios microbianos específicos presentes en estos sistemas (Xiao et al, 2009).

La identificación de altas poblaciones de bacterias fijadoras de nitrógeno en estos humedales

Tabla 2. Resultados de variables fisicoquímicas en los humedales

\begin{tabular}{|c|c|c|c|c|c|c|c|}
\hline \multirow[b]{2}{*}{ Humedal } & \multirow[b]{2}{*}{ Carga* } & \multirow[b]{2}{*}{ Temperatura $\left({ }^{\circ} \mathrm{C}\right)$} & \multirow[b]{2}{*}{$\mathrm{pH}$} & \multicolumn{4}{|c|}{ Análisis Fisicoquímicos } \\
\hline & & & & $\begin{array}{l}\mathrm{DBO} \\
(\mathrm{mg} / \mathrm{L})\end{array}$ & $\begin{array}{l}\text { ORP } \\
(\mathrm{mV})\end{array}$ & $\begin{array}{c}\text { Amonio } \\
(\mathrm{mg} / \mathrm{L})\end{array}$ & $\begin{array}{l}\text { Nitrito } \\
(\mathrm{mg} / \mathrm{L})\end{array}$ \\
\hline & c.h. I & $22.9-241$ & $6.66-7.20$ & $39.0-98.0$ & $-59.3-66.1$ & $29.0-49.0$ & $0.008-0.161$ \\
\hline \multirow{3}{*}{$\begin{array}{l}\text { Helicona } \\
\text { psittacorum }\end{array}$} & c.h. II & $21.7-24.0$ & $6.19-7.10$ & $45.0-97.0$ & $-33.1-59.3$ & $31.0-51.0$ & $0.006-0.156$ \\
\hline & c.h. III & $21.7-22.9$ & $6.23-7.15$ & $40.0-96.0$ & $-45.2-72.3$ & $35.0-50.0$ & $0.006-0.159$ \\
\hline & c.h. I & $21.7-22.4$ & $6.68-7.34$ & $33.0-97.0$ & $-38.3-72.9$ & $29.0-56.3$ & $0.001-0.157$ \\
\hline \multirow[t]{3}{*}{ Sin Vegetación } & c.h. II & $22.9-24.4$ & $6.66-7.10$ & $28.0-100.0$ & $-57.9-66.1$ & $31.0-64.9$ & $0.001-0.161$ \\
\hline & c.h. III & $21.7-24.0$ & $6.80-7.29$ & $27.0-98.0$ & $-49.5-79.5$ & $30.0-63.0$ & $0.002-0.161$ \\
\hline & c.h. I & $21.7-22.9$ & $6.70-7.40$ & $51.0-75.0$ & $-53.2-69.3$ & $29.0-68.9$ & $0.004-0.159$ \\
\hline \multirow{2}{*}{$\begin{array}{l}\text { Phragmites } \\
\text { australis }\end{array}$} & c.h. II & $21.1-24.2$ & $6.53-7.25$ & $52.0-89.0$ & $-45.2-61.2$ & $27.0-65.2$ & $0.003-0.156$ \\
\hline & c.h. III & $21.7-24.0$ & $6.62-6.91$ & $50.0-76.0$ & $-57.9-66.4$ & $31.0-66.2$ & $0.006-0.161$ \\
\hline
\end{tabular}

* Carga hidráulica (ch): I (Qd: $\left.1.7 \mathrm{~m}^{3} \mathrm{~d}^{-}{ }^{1}\right)$; II (Qd: $\left.2.6 \mathrm{~m}^{3} \mathrm{~d}^{-}\right)$y III (Qd: $\left.3.5 \mathrm{~m}^{3} \mathrm{~d}^{-}{ }^{\mathrm{l}}\right)$. 
constituye un ejemplo de una actividad metabólica que no había sido considerada para estos sistemas de tratamiento. Además conforma una fuente de exploración para aplicación en otras de investigación, como por ejemplo la agricultura.

\subsection{Influencia de los parámetros fisicoquímicos}

Las variaciones en los contenidos de nitrógeno (amonio y nitrito), DBO y materia orgánica del agua residual no mostraron un efecto estadísticamente significativo en el crecimiento de los diferentes grupos bacterianos. Se sabe que las variaciones en los microambientes son las que determinan o condicionan el crecimiento de las bacterias (Vymazal, 2007). No se observó interacción con la temperatura (registrada entre los $21^{\circ} \mathrm{C}$ y $24^{\circ} \mathrm{C}$ ) ni el $\mathrm{pH}$ (valores entre 6,197,40 ), ya que los humedales presentaron valores cercanos al óptimo de los grupos evaluados que no influyeron (Lee et al, 2009; Spormann, 2008). Es muy importante tener en cuenta que las mediciones hechas hacen referencia a grupos tróficos y no a especies, posteriores estudios con análisis de diversidad in situ podrían evidenciar estar diferencias y una relación más puntual con los cambios en las condiciones ambientales cercanas a la rizosfera.

\subsection{Influencia de la vegetación, la carga hidráulica y el tipo de muestra}

Las pruebas de medias para el tipo de muestra corroboraron la importancia del sustrato sólido en la formación de biopelículas, lo que generó mayores densidades de los grupos cuantificados en este tipo de muestra.

La carga hidráulica tiene relación directa con la concentración de nutrientes. Al variar este parámetro se proporcionaron distintas concentraciones o flujos másicos de sustratos a los microorganismos. Los resultados fluctuaron para cada humedal, lo que también muestra la influencia del tipo de vegetación. Las bacterias fijadoras y nitrificantes fueron mas abundantes en el humedal con P. australis. Esta es una macrófita con un sistema radicular que presenta adaptaciones a las variaciones de oxígeno que se producen en los humedales (Spormann, 2008). En cuanto a H. Psittacorum se propuso como una especie alterna ya que es una especie autóctona adaptada al clima regional resistente a contaminantes de crecimiento perenne y rápido. Los resultados a nivel microbiológico mostraron que esta especie no tiene características que le permitan óptimos crecimientos a los microorganismos. La poca formación de consorcios se traduce en bajas depuraciones (en este humedal se obtuvieron menores remociones). En los sistemas de tratamiento se busca idealmente la formación de biopelículas de poblaciones mixtas (es decir con presencia de varias especies y/o grupos) (Spormann, 2008), en donde los microorganismos interactúen a nivel de cadenas tróficas, proporcionando los distintos sustratos indispensables para el metabolismo. Konnerup et al (2009) evaluaron la eliminación de nitrógeno y materia orgánica en humedales con esta especie obteniendo tasas muy bajas de conversión.

\section{Conclusiones}

Esta investigación constituye el primer reporte para Colombia sobre las comunidades de bacterias heterótrofas, nitrificantes y fijadoras de nitrógeno presentes en humedales construidos para el tratamiento de agua residual en el trópico.

La carga hidráulica y el tipo de vegetación afectaron la estructura y la abundancia de todos los grupos bacterianos cuantificados. Existe una relación directa entre el flujo de agua y la densidad bacteriana. El humedal con P. australis y control presentaron mayores densidades de microorganismos que el humedal con $H$. Psittacorum.

La gran cantidad de bacterias fijadoras de nitrógeno encontradas al inicio del tratamiento podrían estar relacionadas con la presencia de anmmox y ser responsables de la adición de nitrógeno combinado en los sistemas de humedales construidos, generando balances negativos de eliminación.

El recuento de las bacterias fijadoras es el primer reporte sobre la observación de este proceso Biológico en humedales construidos. 


\section{Referencias bibliográficas}

APHA (American Public Health Association), AWWA (American Water Works Association), WEF (Water Environment Federation), (2005). Standard methods for the examination of water and wastewater. 20th Edition. American Public Health Association. USA.

Bitton, G. (2005). Wastewater Microbiology. New York USA: Wiley Liss.

Block o Bock E. \& Koops H-P. (2006). The genus Nitrobacter and related genera . En: A. Balows, H. G. Trüper, M. Dworkin, W. Harder, \& K.-H. Schleifer (ed.). The prokaryotes 2 nd ed. SpringerVerlag. USA

Brittain T., Blacmore R., Greenwood C. \& Thomson A. (1992). Bacterial nitrite reducing enzymes. European Journal of Biochemistry 209, 793-802

Dixon R. \& Kahn D. (2004). Genetic regulation of biological nitrogen fixation. Nature Reviews 2, 621-631

EPA. (2002). Wastewater Treatment Systems Manual. Office of water office of research and development U.S. Environmental Protection Agency. USA.

Faulwetter J., Gagnon V., Sundberg C., Chazarenc F., Burr M., Brisson J., Camper A. \& Stein O. (2009). Microbial processes influencing performance of treatment wetlands: A review . Ecological Engineering 35, 987-1004

Fowler, G. (1934). An introduction to the biochemistry of nitrogen conservation. Edward Arnold \& Co. London

Gaitán E. (2006). Cuantificación de bacterias nitrificantes, denitrificantes, fijadoras de nitrógeno $y$ heterótrofas de humedales artificiales subsuperficiales para el tratamiento de agua residual. Trabajo pasantia. Universidad del Valle - Universidad de Pamplona.
Konnerup D., Koottatep T., \& Brix H. (2009). Treatment of domestic wastewater in tropical, subsurface flow constructed wetlands planted with Canna and Heliconia. Ecological engineering 35, 248-257

Lee C., Fletcher T. \& Sun G. (2009). Nitrogen removal in constructed wetland systems. Engineering in Life Sciences 9, (1), 1122

Madigan M., Martinko J. \& Parker J. (2004). Brock biología de los microorganismos. Prentice Hall. España

Manser R., Gujer W. \& Siegrist J. (2006). Decay processes of nitrifying bacteria in biological wastewater treatment systems. Water Research 40, 2416-2426

Ministerio del Medio Ambiente: Guía Técnica para el desarrollo de proyectos de reuso de aguas residuales domésticas municipales. Programa de Gestión Ambiental Urbana GAU. Colombia. 2002.

Moat A., Foster J. \& Spector M. (2002). Microbial physiology. Fourth Edition. WileyLiss, Inc. USA.

Montgomery D. (2002). Diseño y análisis de experimentos. Segunda Edición. Limusa Wiley. México, D. F.

Paredes D., Kuschk P., Mbwette T., Stange F., Müller R., \& Köser H. (2007). New aspects of microbial nitrogen transformations in the context of wastewater treatment a review. Engineering in Life Sciences 7 (1), 1325

Pérez-Peláez N. (2006). Cuantificación de bacterias nitrificantes, denitrificantes $y$ heterótrofas de humedales artificiales sub superficiales sometidos a tres cargas hidráulicas y a distinta vegetación. Trabajo de grado. Facultad de Ciencias. Universidad del Valle.

Quipuzco E. (2002).Evaluación del comportamiento de dos pantanos artificiales instalados en serie con Phrag- mites australis para el tratamiento de aguas residuales domésticas. Rev. Inst. Investig. Fac. Minas Metal. Cienc. Geogr 5, 52-57 
Sanabria, J Bedoya, L \& Sánchez, J. (2009). Proceso Anammox una aplicación en Ingeniería: Revisión general de los aspectos microbianos. Ingeniería de Recursos Naturales y del Ambiente $8,69-78$

Sánchez, J. \& Sanabria, J. (2009). Metabolismos microbianos involucrados en procesos avanzados para la remoción de Nitrógeno, una revisión prospectiva. Revista Colombiana de Biotecnología $11(1), 114-124$

Senzia MA, Mashauri DA. \& Mayo, AW. (2003).Suitability of constructed wetlands and waste stabilisation ponds in wastewater treatment: nitrogen transformation and removal. Phys. Chem. Earth (A,B,C). 28(20-27), 1117-1124

Spormann A. (2008). Physiology of microbes in biofilms en: romeo, t. current topics in microbiology and immunology. Bacterial Biofilms. Springer-Verlag 322, 17-36

Stottmeister U., Wiebner P. \& Kuschk P. (2003). Effects of plants and microorganisms in constructed wetlands for wastewater treatment. Biotechnology Advances 22, 93-117
Truu M., Juhanson J., \& Truu J. (2009). Microbial biomass, activity and community composition in constructed wetlands. Science of the Total Environment 407,3958 3971

Vymazal J. (2007). Removal of nutrients in various types of constructed wetlands. Science of the Total Environment 380, 4865

Wetzel R. (2001). Fundamental Processes within natural and constructed wetlands ecosystems: short-term versus long-term objectives. Water Science and Technology 44 (11), 1-8

Xiao Y., Zeng G., Yang Z., Liu Y., Ma Y, Yang, L., Wang, R., \& Xu, Z. (2009). Coexistence of nitrifiers, denitrifiers and Anammox bacteria in a sequencing batch biofilm reactor as revealed by PCR-DGGE. Journal of Applied Microbiology 106, 496-505

Zehr J. P. (2009). New twist on nitrogen cycling in oceanic oxygen minimum zones. Proceedings of the National Academy of Sciences 106, 4575-4576 